\title{
The target of arachidonic acid pathway is a new anticancer strategy for human prostate cancer
}

\author{
Masahide Matsuyama \\ Rikio Yoshimura \\ Department of Urology, Osaka City \\ University Graduate School \\ of Medicine, Osaka, Japan
}

\begin{abstract}
Recent epidemiological studies and animal experiments have demonstrated that nonsteroidal anti-inflammatory drugs (NSAIDs) reduce the incidence of colorectal carcinoma. Cyclooxygenase (COX) is the principal target of NSAIDs. COX is the first oxidase in the process of prostaglandin production from arachidonic acid. COX enzyme may be involved in the initiation and/or the promotion of carcinogenesis due to NSAIDs inhibition of COX. Lipoxygenase (LOX) is also an initial enzyme in the pathway for producing leukotrienes from arachidonic acid. Similar to COX, LOX enzyme may also be involved in the initiation and/or promotion of carcinogenesis. Peroxisome proliferator activator-receptor (PPAR)- $\gamma$ is a ligand-activated transcriptional factor belonging to the steroid receptor superfamily. PPAR- $\gamma$ plays a role in both adipocyte differentiation and carcinogenesis. PPAR- $\gamma$ is one target for cell growth modulation of NSAIDs. In this review, we report the expression of COX-2, LOX and PPAR- $\gamma$ in human prostate cancer tissues as well as the effects of COX-2 and LOX inhibitors and PPAR- $\gamma$ ligand.
\end{abstract}

Keywords: cyclooxygenase, lipoxygenase, peroxisome proliferator activator-receptor- $\gamma$, prostate cancer

\section{Introduction}

Prostate cancer (PC) comprises 32\% of all cancers in American men and is on the increase worldwide. Because of increased screening, PC is frequently diagnosed at a clinically localized stage, making it amenable to the therapy. Nevertheless, it remains the second most common cause of cancer death in men. These patients generally respond to androgen deprivation therapy, but the vast majority eventually experience disease progression and become refractory to sustained hormonal manipulation. Typically, such patients progress with a rise in their serum prostate-specific antigen levels. Unfortunately, standard therapeutic options at this stage of disease are limited, and while there has been some success with chemotherapy for hormone-refractory PC patients, the response is generally short-lived (Oh and Kantoff 1998).

Nonsteroidal anti-inflammatory drugs (NSAIDs) have anticancer effects for the hormone-refractory PC patient, thus, attracting a great deal of attention. The typical target of NSAIDs is cyclooxygenase (COX). In recent reports, a number of patients have had significantly low risks of colorectal cancer while they continued using NSAIDs typified by aspirin. Consequently, the suppression of carcinogenesis by administering NSAIDs has come into focus. It was also reported that the size and number of adenoma were markedly reduced when sulindac, a type of NSAIDs was given to patients with familial adenomatous polyposis, a high risk group for colorectal cancer (Sano et al 1995).

It is known that NSAIDs inhibit the activity of COX and production of prostaglandin. NSAIDs also stimulate peroxisome proliferator activator-receptor (PPAR)- $\gamma$ and inhibit the production of chemical mediators such as tumor necrosis factor- $\alpha$, 
interleukin-1 $\beta$ and interleukin- 6 through the expression of PPAR- $\gamma$ in leukocytes. PPAR- $\gamma$ is thus a promising target for cell growth modulation by NSAIDs.

In this review, we discuss the possibility that the target of arachidonic acid pathway metabolite may be a new anticancer strategy for human PC.

\section{Arachidonic acid pathway (cyclooxygenase and lipoxygenase)}

The metabolism of arachidonic acid by either COX pathway or lipoxygenase (LOX) pathway generates eicosanoids, which have been implicated in the pathogenesis of a variety of human diseases, including cancer, and are considered important in tumor promotion, progression, and metastasis (Yoshimura et al 2003).

COX is the first enzyme in the pathway for producing prostaglandin (PG) and thromboxane (Tx) from arachidonic acid, and can occur as three isoforms, COX-1, COX-2, and COX-3. The enzymes of both COX-1 and COX-2 are transformed from the cell membrane phospholipid to arachidonic acid by the phospholipase $\mathrm{A}_{2}$, and then transform arachidonic acid to $\mathrm{PGH}_{2}$ through $\mathrm{PGG}_{2}$ (Figure 1). COX-1 occurs in tissues and cells and works to protect the cell. COX-2 expresses momentarily and strongly in response to growth factors and some endotoxins. It is involved with inflammation, cell proliferation and differentiation (Xie et al 1991). Recently, COX-2 has also been shown to play an important role in carcinogenesis (Sano et al 1995). Although the existence of COX-3 has recently been reported, it continues to be debated.

LOX is the first enzyme in the pathway for producing leukotriene (LT) from arachidonic acid. Isoenzymes of LOX include 5-LOX, 12-LOX, and two 15-LOX isoforms (15-LOX-1, 15-LOX-2). These catalyze the biosynthesis of biologically active compounds such as LTs and hydroxyeicosatetraenoic acids (HETEs) (Sigal 1991; Funk 1996). 5-LOX catalyzes the first step in oxygenation of arachidonic acid to produce 5-hydroperoxyeicosatetraenoic acid (5-HPETE), and the subsequent metabolism of 5-HPETE to 5-HETE and LTs (Figure 1). LTs belong to an important group of pro-inflammatory mediators that are synthesized from arachidonic acid via the 5-LOX pathway. The activity of 5-LOX leads

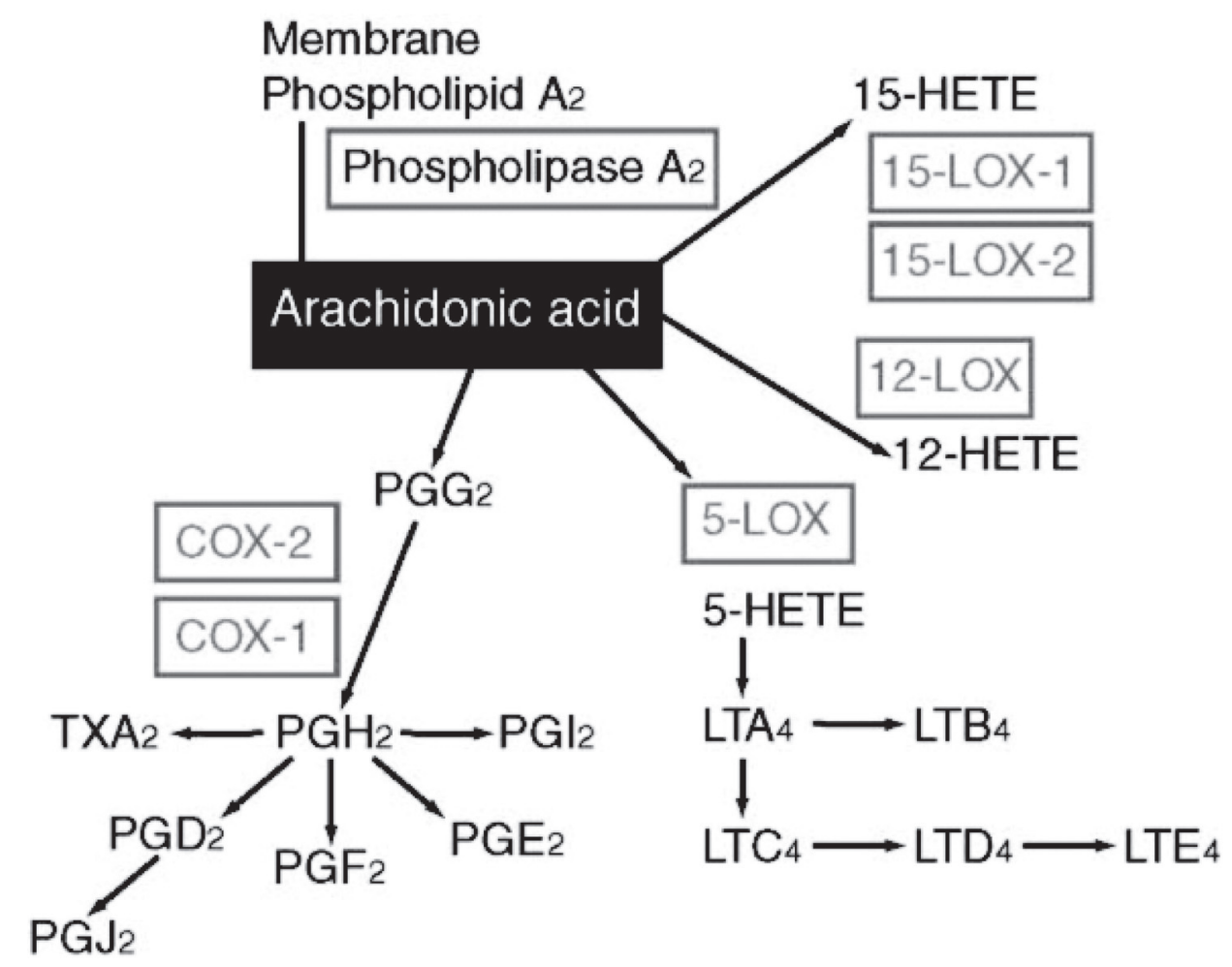

Figure I Map of arachidonic acid (AA) cascade. Cyclooxygenase (COX) is the first enzyme in the pathway for producing prostaglandin (PG) and thromboxane (Tx) from arachidonic acid. COX-I is present in most tissues and involved in the physiological production of PGs for maintaining normal homeostasis. COX-2, which is induced by mitogens, cytokines, and growth factors, is primarily responsible for PGs produced in inflammatory sites. Lipoxygenase (LOX) is the first enzyme in the pathway for producing leukotrien (LT) from arachidonic acid. Isoenzymes of LOX include 5-LOX, I2-LOX, and two I5-LOX isoforms (I5-LOX-I, I5-LOX-2). 
to the formation of unstable $\mathrm{LTA}_{4}$, which can be converted into either $\mathrm{LTB}_{4}$, or cysteinyl LTs $\left(\mathrm{LTC}_{4}, \mathrm{LTD}_{4}\right.$ and $\left.\mathrm{LTE}_{4}\right)$ (Matsuyama et al 2007).

The 12-LOX, includes platelet 12-LOX, and leukocyte 12-LOX that oxygenate arachidonic acid at position C-12 to produce 12-hydroperoxyeicosatetra-enoic acid and then 12-HETE (Yoshimura et al 2003). Whereas 5-LOX, 12-LOX, and 15-LOX-1, have pro-carcinogenic roles, 15-LOX-2 appears to have an anticarcinogenic role.

\section{Peroxisome proliferator activator-receptor}

Peroxisome proliferator activator-receptors are members of the nuclear receptor super-family of ligand-activated transcriptional factor such as steroids, thyroid hormone, vitamin $\mathrm{D}_{3}$ and retinoic acid (Issemann and Green 1990). PPAR binds to peroxisome proliferator response element (PPRE) as a heterodimer with the retinoic receptor ( $R X R)$ in the regulation of PPAR target genes (Figure 2). PPARs may be important immunomodulatory factors as well as fatty acid regulators. PPARs modulate these activities in different immune cell types such as monocyte/macrophages, lymphocytes, and endothelial cells.

Three PPAR subtypes ( $\alpha, \beta$, and- $\gamma$ ) have been identified. PPAR- $\alpha$ is highly expressed in the liver, heart, kidney, muscle, brown adipose tissue, and gut tissues which exhibit high carbolic rates towards fatty acid (Braissant et al 1996). PPAR- $\beta$ is expressed ubiquitously, and its function is relatively unknown (Mukherjee et al 1997). Recent studies suggest that PPAR- $\beta$ may be a target for NSAID-induced tumor suppression in colorectal tumors. PPAR- $\gamma$ is expressed at high-level in adipose tissue and is a critical regular of adipocyte differentiation. In addition, PPAR- $\alpha$, and $-\gamma$ may be important immunomodulatory factors. PPAR- $\alpha$-knockout mice exhibit exacerbated inflammatory responses, and $\mathrm{LTB}_{4}$, a chemotactic mediator, seems to regulate the clearance of itself as an agonist of PPAR- $\alpha$. PPAR $-\gamma$ is also expressed in the immune system tissues and cells (spleen, bone-marrow, monocytes, helper T-cell clones) and skeletal tissues (bone, synovioum, chondrocytes) (Braissant et al 1996).

Recent data have shown that PPAR- $\gamma$ ligands lead to inhibition of phorbol ester-induced nitric oxide and macrophagederived cytokines. PPAR- $\gamma$ ligands also induce apoptosis in macrophage, fibroblasts, and endothelial cells (Kawahito et al 2000). PPAR- $\gamma$ plays a role in both adipocyte differentiation and carcinogenesis. PPAR- $\gamma$ ligands lead to inhibition of the expression of nitric oxide, cytokines, chemokines and adhesion molecules, in part by antagonizing the activities of transcriptional factors. Furthermore, PPAR- $\gamma$ ligands including antidiabetic thiazolidinedione (such as troglitazone) and 15 -deoxy- $\Delta^{12,14}$-prostaglandin $\mathrm{J}_{2}\left(15-\mathrm{d}-\mathrm{PGJ}_{2}\right)$ have potent

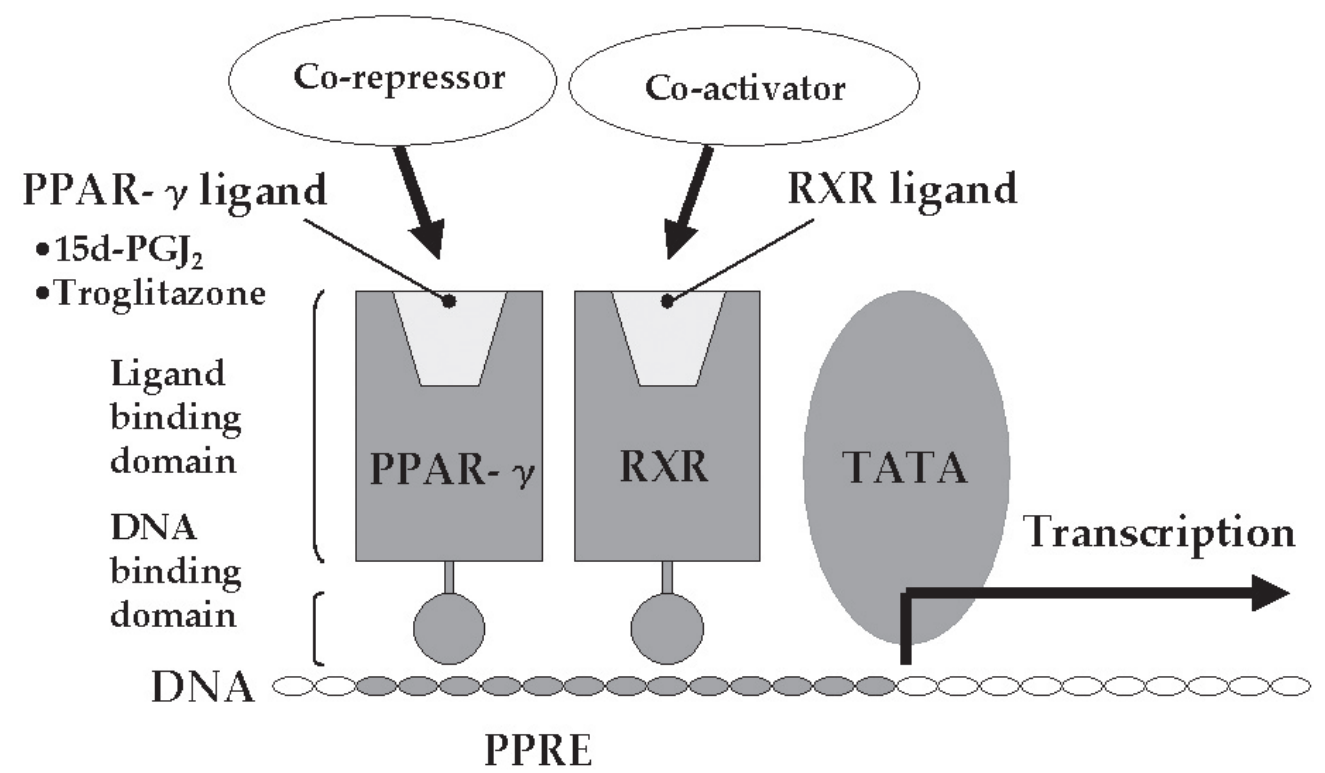

Figure 2 Mechanism of PPAR- $\gamma$ ligand.PPAR- $\gamma$ are members of the nuclear receptor super-family of ligand-activated transcriptional factor.PPAR binds to peroxisome proliferator response element (PPRE) as a heterodimer with the retinoic receptor (RXR), implying a role of 9-cis retinoic acid in PPAR target gene regulation. 
tumor modulatory effects on several cancers (Tsubouchi et al 2000; Inoue K et al 2001).

\section{COX and PC}

COX-2 expression in PC tissues is stronger than in the normal prostate (NP), benign prostate hyperplasia $(\mathrm{BPH})$, and prostatic intraepithelial neoplasia (PIN) tissues, whereas there are no significant differences among $\mathrm{COX}-1$ expression in NP, BPH, PIN, or PC tissues by immunohistochemical staining (28 PC, 1 PIN, 8 BPH and 8 NP tissues) or RTPCR (Figure 3). There were no significant differences in the intensity of COX-1 among NP, BPH, PIN and PC tissues. However, only in epithelium of $\mathrm{PC}$ tissues, COX-2 expression was more intensive and extensive than that in NP, BPH and PIN tissues, and COX-2 expression was stronger in low differentiation PC (Yoshimura et al 2000). Gupta and colleagues (2000) reported COX-2 expression was stronger than COX-1 in PC by immunohistochemical staining and RT-PCR. Kirschenbaum and colleagues (2000) reported both COX-1 and COX-2 expressions in PC tissues were stronger than those in NP tissues by immunohistochemical staining.

Vascularization of tumors is closely linked to the expression of COX-2 in tumors. Apoptosis is induced in tumor cell in response to drugs which inhibit vascularization. Angiogenesis factors such as vascular endothelial growth factor and transforming growth factor beta are induced by COX-2 expression. Liu and colleagues (2000) reported suppressing vascular endothelial growth factor and inducing apoptosis in nude mouse xenografts of the human PC cell line (PC3) with three intraperitoneal injection of the COX-2 inhibitor NS398 (3 mg/kg) over 9 week. In these studies, Bcl-2 was found to be a key apoptosis suppressing factor. In contrast, Hsu and colleagues (2000) reported that growth inhibition of PC-3 and LNCaP cells by selective COX-2 inhibitor celecoxib was associated with down-regulation of Bcl-2. COX-2 inhibition results in down-regulation of the nuclear factor- $\lambda \mathrm{B}$, or the activation of PPAR- $\gamma$, apoptosis activating factor-1, and caspase- 3 (Narayanan et al 2003).

A recently accepted explanation is that only celecoxib, among the COX-2 inhibitors induces apoptosis of cancer cells. Andrews and colleagues (2008) reported celecoxib was most effective in decreasing cell growth and inducing apoptosis at the lowest dosages in several NSAIDs. Narayanan and colleagues (2006) reported celecoxib had a dose-dependent effect against transgenic adenocarcinoma in mouse prostate. Patel and colleagues (2005) reported the anticancer activity of celecoxib may reflect $\mathrm{COX}$-2-independent in addition to COX-2-dependent effects.

In our experiment, we could not demonstrate significant apoptosis induction by administering eight kinds of COX-2 inhibitors into the human PC cell lines (PC3, DU-145) (Table 1).

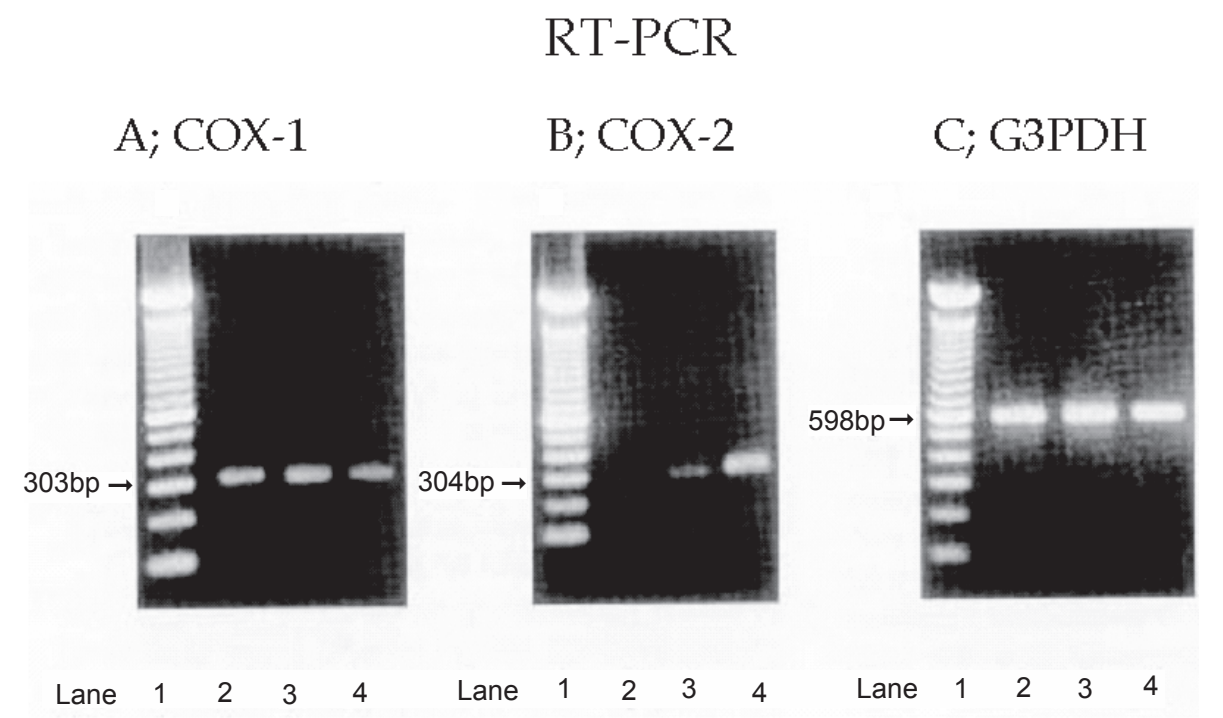

\section{Lane 1; marker, Lane 2; NP, Lane 3; BPH, Lane 4; PC}

Figure 3 RT-PCR analysis of COX-I and COX-2 in prostate tissues. We detected the specific band of COX-I protein in all samples (A, lane 2, 3, 4). However, we detected the specific band of COX-2 protein in samples from prostate cancer (B, lane 4), while a sample from BPH displayed a very weak band (B, lane 3), and a sample from normal prostate displayed no clear band (B, lane 2 ) in the study. 
Table I Effects of COX and LOX inhibitors, and PPAR- $\gamma$ ligand in viability of human prostate cancer cells

\begin{tabular}{|c|c|c|c|c|c|c|}
\hline COX inhibitors & PC cel line & $5 \mu \mathrm{M}$ & $10 \mu \mathrm{M}$ & $20 \mu \mathrm{M}$ & $40 \mu \mathrm{M}$ & $80 \mu \mathrm{M}$ \\
\hline \multirow[t]{2}{*}{ Etodolac } & PC3 & not shown & $93.6 \%$ & $88.3 \%$ & $89.1 \%$ & $77.5 \%$ \\
\hline & DU-I45 & not shown & $105.1 \%$ & $106.7 \%$ & $104.4 \%$ & $95.1 \%$ \\
\hline \multirow[t]{2}{*}{ Nimesulide } & PC3 & not shown & $83.1 \%$ & $91.5 \%$ & $78.1 \%$ & $94.1 \%$ \\
\hline & DU-I45 & not shown & $110.1 \%$ & $99.1 \%$ & $99.8 \%$ & $105.9 \%$ \\
\hline \multicolumn{7}{|l|}{ LOX inhibitors } \\
\hline \multirow[t]{2}{*}{ 5-LOX inhibitor } & PC3 & not shown & $112.5 \%$ & $96.7 \%$ & $78.8 \%$ & $45.3 \%$ \\
\hline & DU-I45 & not shown & $80.7 \%$ & $69.2 \%$ & $22.2 \%$ & $8.1 \%$ \\
\hline \multirow[t]{2}{*}{ 12-LOX inhibitor } & PC3 & not shown & $117.8 \%$ & $100.2 \%$ & $103.8 \%$ & $76.5 \%$ \\
\hline & DU-I 45 & not shown & $102.4 \%$ & $99.1 \%$ & $85.1 \%$ & $63.5 \%$ \\
\hline \multirow[t]{2}{*}{ Non selective LOX inhibitor } & PC3 & not shown & $113.0 \%$ & $101.7 \%$ & $51.1 \%$ & $18.5 \%$ \\
\hline & DU-I 45 & not shown & $67.7 \%$ & $42.3 \%$ & $9.9 \%$ & $5.2 \%$ \\
\hline \multicolumn{7}{|l|}{ PPAR- $\gamma$ ligands } \\
\hline \multirow[t]{2}{*}{ Troglitazone } & PC3 & $48.6 \%$ & $15.5 \%$ & $14.7 \%$ & $6.5 \%$ & not shown \\
\hline & DU-I 45 & $60.1 \%$ & $35.1 \%$ & $7.6 \%$ & $7.7 \%$ & not shown \\
\hline \multirow[t]{2}{*}{$15 d-P G \mid 2$} & PC3 & $69.7 \%$ & $59.0 \%$ & $34.1 \%$ & $6.8 \%$ & not shown \\
\hline & DU-I45 & $73.8 \%$ & $59.3 \%$ & $5.8 \%$ & $5.8 \%$ & not shown \\
\hline
\end{tabular}

Notes: The dose-response analysis of viability in human prostate cancer cells treated with COX and LOX inhibitors, and PPAR- $\gamma$ ligands (5-80 $\mu$ M, $48 \mathrm{hr})$ was measured by the MTT assay and expressed as \% of control culture conditions.

Additionally, we could not demonstrate the significance of both selective COX-2 inhibitor and relatively poor selective COX-2 inhibitor (Yoshimura et al 2004).

In conclusion, $\mathrm{COX}-2$ expression is strong in $\mathrm{PC}$, but the anticancer effect of COX-2 inhibitor is very weak in PC and hormone-refractory $\mathrm{PC}$ patients in a single administration at a clinical dose. COX-2 inhibitor is suitable for chemopreventive therapy.

\section{LOX and PC}

We have shown that 5- and 12-LOX expressions in PC and PIN tissue are stronger than those in NP and BPH tissues by immunohistochemical staining (174 PC, 20 PIN, $20 \mathrm{BPH}$, and $20 \mathrm{NP}$ tissues) and RT-PCR. We classified 3 categories (epithelium, blood vessel, stromal tissue) in $\mathrm{NP}, \mathrm{BPH}, \mathrm{PIN}$, and PC tissues, and examined the intensity of 5- and 12-LOX expressions. 5- and 12-LOX expressions were more intensive and extensive in all categories of $\mathrm{PC}$ and PIN tissues as compared with NP and BPH tissues (Table 2). There were no significant differences between 5- and 12-LOX expressions in grades (Matsuyama et al 2004a). Consistent with our findings, Kelavkar and colleagues (2004) reported 15-LOX-1 is expressed in NP and increased in PC, especially high-grade PC. At $10-80 \mu \mathrm{M}$, some, but not all LOX inhibitors reduced the viability of PC3 and DU-145 cell lines by MTT assay (Table 1). Some
LOX inhibitors induced apoptosis in PC cells at $50 \mu \mathrm{M}$. 5-LOX inhibitor appeared more potent than the 12-LOX inhibitor (Matsuyama et al 2004a, 2004b).

Several papers have reported that LOX inhibitors are candidates for the development as new chemopreventive or chemotherapeutic strategies for PC. Ghosh and Myers

Table 2 Statistical analysis of 5-LOX and 12-LOX immunostaining

\begin{tabular}{llll}
\hline & Epithelium & Blood vessel & Stromal tissue \\
\hline 5-LOX & & & \\
PC & $2.5 \pm 1 . I^{*}$ & $2.2 \pm 1.0^{*}$ & $2.2 \pm 0.9^{*}$ \\
Low group & $2.2 \pm 1.4^{*}$ & $2.2 \pm 1.4^{*}$ & $2.0 \pm 0.8^{*}$ \\
Middle group & $2.7 \pm 1.0^{*}$ & $2.7 \pm 1.0^{*}$ & $2.2 \pm 1.2^{*}$ \\
High group & $2.6 \pm 1.2^{*}$ & $2.6 \pm 1.2^{*}$ & $2.4 \pm 0.7^{*}$ \\
PIN & $2.1 \pm 1.1^{*}$ & $2.0 \pm 1.4^{*}$ & $1.9 \pm 1.1^{*}$ \\
BPH & $0.5 \pm 0.5$ & $0.6 \pm 0.5$ & $0.6 \pm 0.5$ \\
NP & $0.5 \pm 0.5$ & $0.5 \pm 0.5$ & $0.5 \pm 0.4$ \\
I2-LOX & & & \\
PC & $2.2 \pm 1.0^{*}$ & $2.2 \pm 1.2^{*}$ & $2.2 \pm 0.9^{*}$ \\
Low group & $2.0 \pm 1.2^{*}$ & $2.0 \pm 1.2^{*}$ & $1.8 \pm 0.7^{*}$ \\
Middle group & $2.4 \pm 1.2^{*}$ & $2.4 \pm 1.2^{*}$ & $2.6 \pm 1.0^{*}$ \\
High group & $2.3 \pm 0.9^{*}$ & $2.3 \pm 0.9^{*}$ & $2.2 \pm 0.9^{*}$ \\
PIN & $1.9 \pm 1.3^{*}$ & $1.8 \pm 1.4^{*}$ & $1.8 \pm 1.1^{*}$ \\
BPH & $0.8 \pm 0.5$ & $0.7 \pm 0.5$ & $0.5 \pm 0.5$ \\
NP & $0.6 \pm 0.4$ & $0.5 \pm 0.4$ & $0.5 \pm 0.4$ \\
\hline
\end{tabular}


(1998) reported that inhibition of arachidonate 5-LOX triggers massive apoptosis in both androgen-sensitive (LNCaP) and androgen-refractory (PC3) human PC cells. The metabolites of arachidonate 5-LOX promoted survival of PC cells involving down-regulation of stress-activated protein kinase (Ghosh 2003). Furthermore, concern about combination 5-LOX inhibitor and other target, Pommery and colleagues (2004) reported dual COX-2/5-LOX inhibitors induce agents potentially useful in prostate cancer chemotherapy through apoptosis (Pommery et al 2004). Ghosh J et al reported the combination of selenium and 5-LOX inhibitors may be a more effective regimen for PC control (Ghosh 2004). Narayanan and colleagues (2007) reported Licofelone inhibited COX-2 and 5-LOX simultaneously and prevented overall cancer cell growth by enhancing apoptosis in both androgen-dependent and androgen-independent PC cells. Yoshida and colleagues (2007) reported LOX inhibitors augment the apoptotic efficiency of tumor necrosis factor-related apoptosis-inducing ligand through death receptor 5 up-regulation in malignant tumor cells.

In conclusion, 5-LOX expression is strong in PC, especially high-grade PC. The anticancer effect of 5-LOX inhibitor is significantly stronger than those of COX-2 inhibitor. The anticancer effect of 5-LOX inhibitor is weak in PC and hormone-refractory PC patients in a single administration at a clinical dose. 5-LOX inhibitor is suitable for chemopreventative therapy like the COX-2 inhibitor.

\section{PPAR $-\gamma$ and PC}

By immunohistochemical staining (Figure 4), and RT-PCR, PPAR- $\gamma$ expression is increased in PC and PIN tissues as
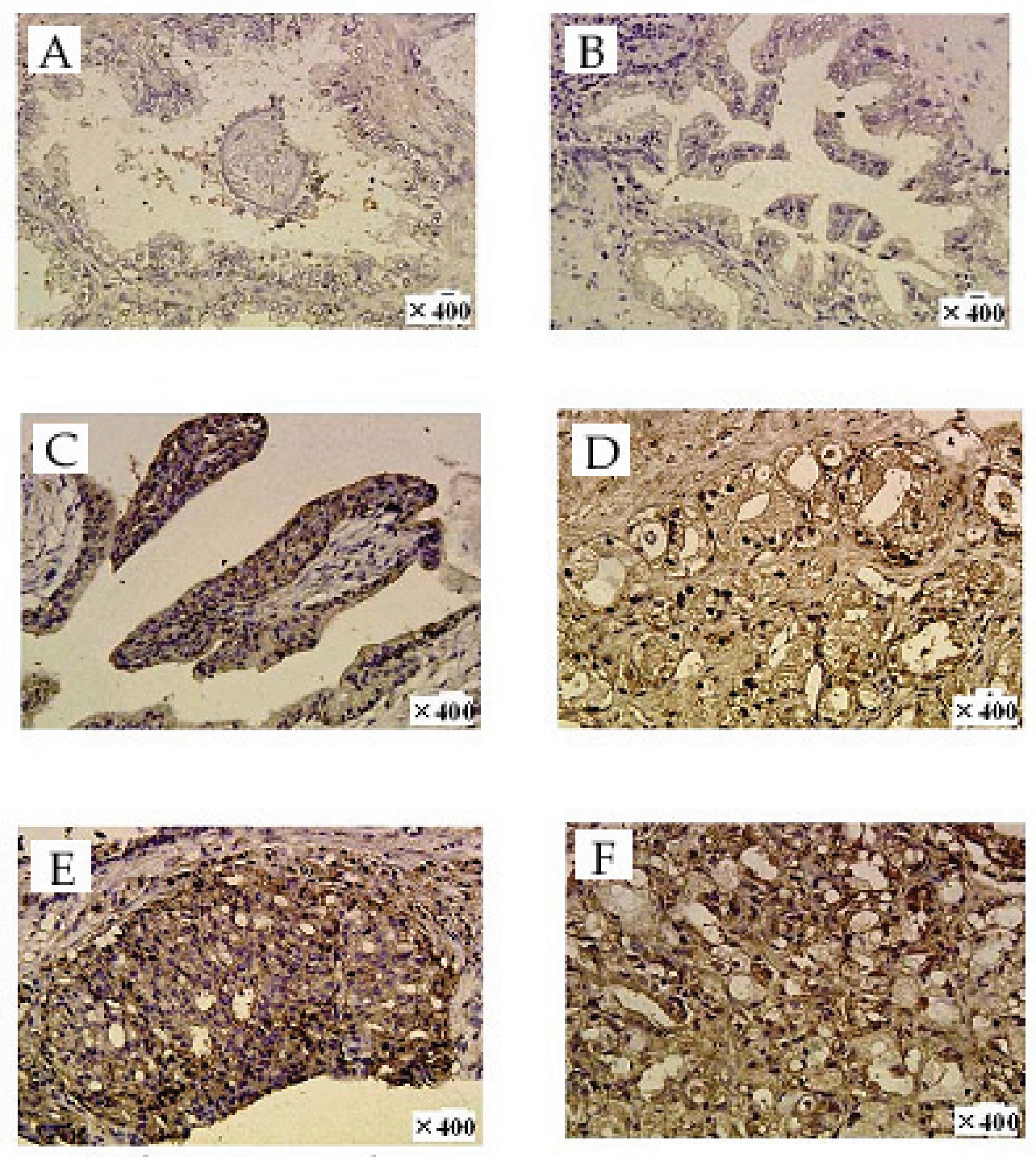

Figure 4 Representative immunostaining for PPAR- $\gamma$ in prostate tissues samples. We detected significant strong PPAR- $\gamma$ expression in all PC (D; GI, E; G2, F, G3) group tissues and PIN (C) tissue, whereas PPAR- $\gamma$ expression was very weak in BPH (B) tissue and NP (A) tissue. 
compared with BPH and NP tissues (156 PC, 15 PIN, 20 BPH, and 12 NP tissues). In epithelium, blood vessel, stromal tissue of PC, PIN, BPH, and NP tissues, the intensity of PPAR- $\alpha,-\beta$, and $-\gamma$ expression was not significantly different. In the parenchyma, PPAR- $\gamma$ expression was significantly greater in PC and PIN tissues than in BPH and NP tissues. In our studies, PPAR- $\gamma$ expression was higher in G3 cancer than in G1 cancer (Segawa et al 2002). In contrast, Paltoo and colleagues (2003) were unable to detect significant differences in PPAR- $\gamma$ expression across grades and stages, perhaps due to technical limitations.

The PPAR- $\gamma$ ligands troglitazone and $15-\mathrm{d}-\mathrm{PGJ}_{2}$ induced the reduction of PC3 and DU-145 viability in the range of $10-40 \mu \mathrm{M}$ by using MTT assay (Table 1). PC cells treated with PPAR- $\gamma$ ligands ( $25 \mu \mathrm{M}$ troglitazone and $\left.15-\mathrm{d}_{-}-\mathrm{FJ}_{2}\right)$ entered early apoptosis, but not late apoptosis, necrosis or DNA fragmentation by flow cytometry (Figure 5) (Matsuyama and Yoshimura 2008). However, PPAR- $\gamma$ ligands did not cause normal prostate epithelial cells to undergo apoptosis. Subbarayan and colleagues (2004) also reported similar results. Several reports support a similar degree of efficacy of PPAR- $\gamma$ ligands in PC (Butler et al 2000; Chaffer et al 2006).
In conclusion, PPAR- $\gamma$ is strongly expressed in PC, and the anticancer effect of PPAR- $\gamma$ ligand is significantly greater than that of 5-LOX inhibitor. The anticancer effect of PPAR- $\gamma$ ligand is relatively week. Targeting PPAR- $\gamma$ in PC is likely to be useful more as a chemopreventive rather than a chemotherapeutic.

\section{Conclusions}

There is no argument that COX-2, LOX (especially, 5-LOX) PPAR- $\gamma$ are involved in the initiation and promotion of PC tissues. It may be possible to use COX-2 and 5-LOX inhibitors, and PPAR- $\gamma$ ligand as anticancer drugs for chemopreventive therapy in a single administration of a clinical dose. However, it may be difficult to use COX-2 and 5-LOX inhibitors, even with PPAR- $\gamma$ ligand in single administration of a clinical dose as a potential chemotherapeutic therapy. The clinical application of PPAR- $\gamma$ ligand and 5-LOX inhibitor require further research and consideration, as the target of PPAR- $\gamma$ ligand and 5-LOX inhibitor remains a novel strategy in treating human PC.

We conclude the administration of COX-2 and 5-LOX inhibitor, and PPAR- $\gamma$ ligand are useful along with conventional

(A)

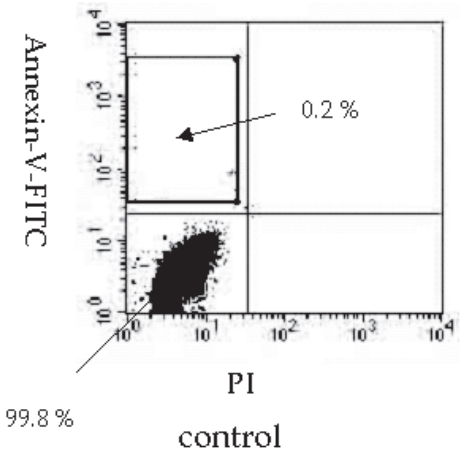

(B)

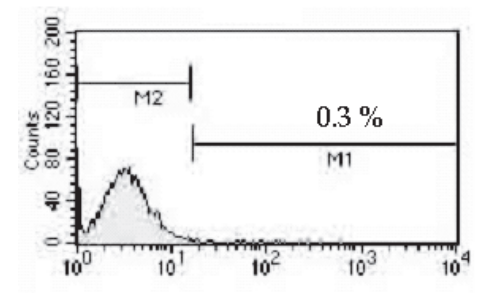

dUTP FITC

control

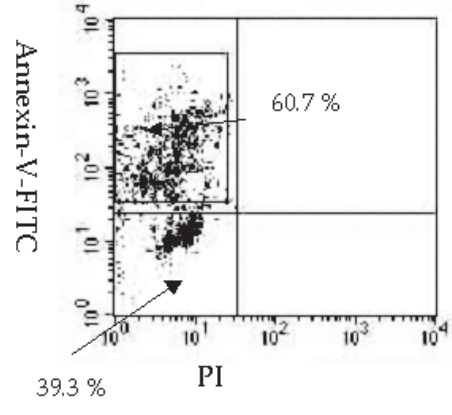

25 $\mu \mathrm{M}$ PPAR ligand

$\left(15-\mathrm{d}-\mathrm{PG} \mathrm{J}_{2}\right)$

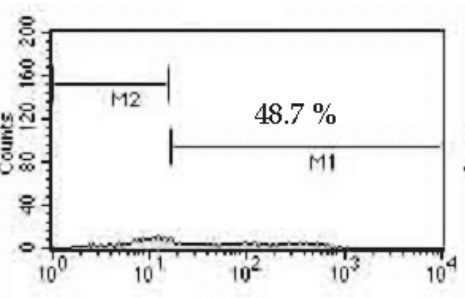

dUTP FITC

$25 \mu \mathrm{M}$ PPAR ligand

$\left(15-\mathrm{d}-\mathrm{PGJ}_{2}\right)$

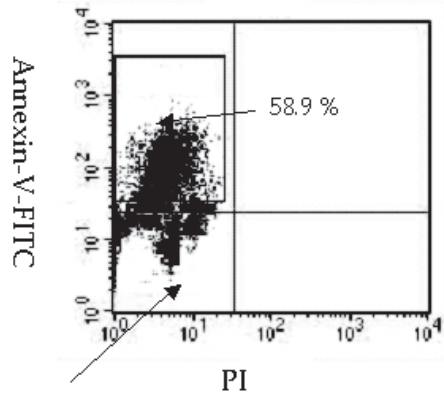

$44.1 \% \quad 25 \mu \mathrm{M}$ PPAR ligand

(Troglitazone)

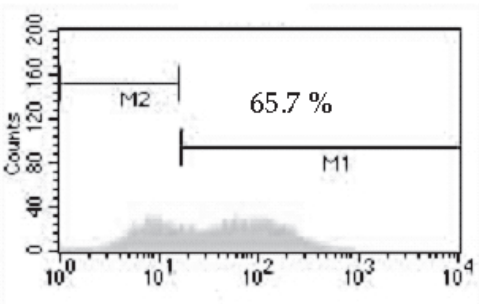

dUTP FITC

25 MMPPAR ligand

(Troglitazone)

Figure 5 Effects of PPAR- $\gamma$ ligands on apoptosis by flow cytometry in PC cell line. Treatment with $25 \mu M$ PPAR- $\gamma$ ligands (troglitazone and I5-d-PG ${ }_{2}$ ) induced early apoptosis not late apoptosis or necrosis in PC cell line (PC3). The top left quadrants represent early apoptosis. Diagrams of FITC-Annexin V/PI flow cytometry are presented (A). Treatment with $25 \mu$ M PPAR- $\gamma$ ligands (troglitazone and I5-d-PG ${ }_{2}$ ) could induce DNA fragmentation in PC cell line (PC3). Typical flow cytometry analysis histograms are presented (B). 
treatment of human PC. The combination therapy of COX-2 and 5-LOX inhibitor, and PPAR- $\gamma$ ligand may be a benefical new treatment of human PC.

\section{Acknowledgments}

This manuscript was edited by Hilah Edney, BS, MS. The authors report no conflicts of interest in this work.

\section{References}

Andrews P, Zhao X, Allen J, et al. 2008. A comparison of the effectiveness of selected non-steroidal anti-inflammatory drugs and their derivatives against cancer cells in vitro. Cancer Chemother Pharmacol, 61:203-14.

Braissant O, Foufelle F, Scotto C, et al. 1996. Differential expression of peroxisome proliferator-activated receptors (PPARs). Tissue distribution of PPARalpha, -beta, and -gamma in the adult rat. Endocrinology, 137:354-66.

Butler R, Mitchell SH, Tindall DJ, et al. 2000. Nonapoptotic cell death associated with S-phase arrest of prostate cancer cells via the peroxisome proliferator-activated receptor gamma ligand, 15-deoxydelta12,14-prostaglandin $\mathrm{J}_{2}$. Cell Growth Differ, 11:49-61.

Chaffer CL, Thomas DM, Thompson EW, et al. 2006. PPAR gammaindependent induction of growth arrest and apoptosis in prostate and bladder carcinoma. BMC Cancer, 6:53.

Devchand PR, Keller H, Peters JM, et al. 1996. The PPARalpha-leukotriene B4 pathway to inflammation control. Nature, 384:39-43.

Funk CD. 1996. The molecular biology of mammalian lipoxygenases and the quest for eicosanoid functions using lipoxygenase-deficient mice. Biochim Biophys Acta, 11:65-84.

Ghosh J, Myers CE. 1998. Inhibition of arachidonate 5-lipoxygenase triggers massive apoptosis in human prostate cancer cells. Proc Natl Acad Sci USA, 95:13182-7.

Ghosh J. 2003. Inhibition of arachidonate 5-lipoxygenase triggers prostate cancer cell death through rapid activation of c-Jun N-terminal kinase. Biochem Biophys Res Commun, 307:342-9.

Ghosh J. 2004. Rapid induction of apoptosis in prostate cancer cells by selenium: reversal by metabolites of arachidonate 5-lipoxygenase. Biochem Biophys Res Commun, 315:624-35.

Gupta S, Srivastava M, Ahmad N, et al. 2000. Over-expression of cyclooxygenase-2 in human prostate adenocarcinoma. Prostate, 42:73-8.

Hsu AL, Ching TT, Wang DS, et al. 2000. The cyclooxygenase-2 inhibitor celecoxib induces apoptosis by blocking Akt activation in human prostate cancer cells independently of Bcl-2. J Biol Chem, 275:11397-403.

Inoue K, Kawahito Y, Tsubouchi Y, et al. 2001. Expression of peroxisome proliferator-activated receptor gamma in renal cell carcinoma and growth inhibition by its agonists. Biochem Biophys Res Commun, 287:727-32.

Issemann I, Green S. 1990. Activation of a member of the steroid hormone receptor superfamily by peroxisome proliferator. Nature, 347:645-50

Kawahito Y, Kondo M, Tsubouchi Y, et al. 2000. 15-deoxy-delta(12,14)PGJ(2) induces synoviocyte apoptosis and suppresses adjuvant-induced arthritis in rats. J Clin Invest, 106:189-97.

Kelavkar UP, Glasgow W, Olson SJ, et al. 2004. Overexpression of 12/15-lipoxygenase, an ortholog of human 15-lipoxygenase-1, in the prostate tumors of TRAMP mice. Neoplasia, 6:821-30.

Kirschenbaum A, Klausner AP, Lee R, et al. 2000. Expression of cyclooxygenase- 1 and cyclooxygenase- 2 in the human prostate. Urology, 56:671-6.

Liu XH, Kirschenbaum A, Yao S, et al. 2000. Inhibition of cyclooxygenase-2 suppress angiogenesis and the growth of prostate cancer in vivo.J Urol, 164:820-5.

Matsuyama M, Yoshimura R, Mitsuhashi M, et al. 2004a. Expression of lipoxygenase in human prostate cancer and growth reduction by its inhibitors. Int J Oncol, 24:821-7.
Matsuyama M, Yoshimuira R, Tsuchida K, et al. 2004b. Lipoxygenase inhibitors prevent urological cancer cell growth. Int J Mol Med, 13:665-8.

Matsuyama M, Hayama T, Funao K, et al. 2007. Overexpression of cysteinylLT1 receptor in prostate cancer and CysLT1R antagonist inhibits prostate cancer cell growth through apoptosis. Oncol Rep, 18:99-104.

Matsuyama M, Yoshimura R. 2008. Peroxisome proliferator-activated receptor- $\gamma$ is a potent target for prevention and treatment in human prostate and testicular cancer. PPAR Res, 2008:249849.

Mukherjee R, Jow L, Croston GE, et al. 1997. Identification, characterization, and tissue distribution of human peroxisome proliferator-activated receptor (PPAR) isoforms PPARgamma2 versus PPARgamma1 and activation with retinoid $\mathrm{X}$ receptor agonists and antagonists. $J$ Biol Chem, 272:8071-6.

Narayanan BA, Condon MS, Bosland MC, et al. 2003. Suppression of $\mathrm{N}$-methyl-N-nitrosourea/testosterone-induced rat prostate cancer growth by celecoxib: effects on cyclooxygenase-2, cell cycle regulation, and apoptosis mechanism(s). Clin Cancer Res, 9:3503-13.

Narayanan BA, Narayanan NK, Pttman B, et al. 2006. Adenocarcina of the mouse prostate growth inhibition by celecoxib: downregulation of transcription factors involved in COX-2 inhibition. Prostate, 66:257-65.

Narayanan NK, Nargi D, Attur M, et al. 2007. Anticancer effects of licofelone (ML-3000) in prostate cancer cells. Anticancer Res, 27:2393-402.

Oh WK, Kantoff PW. 1998. Management of hormone refractory prostate cancer: current standards and future prospects. J Urol, 160:1220-9.

Paltoo D, Woodson K, Taylor P, et al. 2003. Pro12Ala polymorphism in the peroxisome proliferator-activated receptor-gamma (PPAR-gamma) gene and risk of prostate cancer among men in a large cancer prevention study. Cancer Lett, 191:67-74.

Patel MI, Subbaramaiah K, Du B, et al. 2005. Celecoxib inhibits prostate cancer growth: evidence of a cyclooxygenase-2-independent mechanism. Clin Cancer Res, 11:1999-2007.

Pommery N, Taverne T, Telliez A, et al. 2004. New COX-2/5-LOX inhibitors: apoptosis-inducing agents potentially useful in prostate cancer chemotherapy. J Med Chem, 47:6195-206.

Sano H, Kawahito Y, Wilder RL, et al. 1995. Expression of cyclooxygenase1 and -2 in human colorectal cancer. Cancer Res, 55:3785-9.

Segawa Y, Yoshimura R, Hase T, et al. 2002. Expression of peroxisome proliferator-activated receptor (PPAR) in human prostate cancer. Prostate, 51:108-16.

Sigal E. 1991. The molecular biology of mammalian arachidonic acid metabolism. Am J Physiol, 260:13-28.

Subbarayan V, Sabichi AL, Kim J, et al. 2004. Differential peroxisome proliferator-activated receptor-gamma isoform expression and agonist effects in normal and malignant prostate cells. Cancer Epidemiol Biomarkers Prev, s13:1710-16.

Tsubouchi Y, Sano H, Kawahito Y, et al. 2000. Inhibition of human lung cancer cell growth by the peroxisome proliferator-activated receptor- $\gamma$ agonists through induction of apoptosis. Biochem Biophys Res Commun, 270:400-5.

Xie W, Chipman JG, Robertson DL, et al. 1991. Expression of a mitogenresponsive gene encoding prostaglandin synthase is regulated by mRNA splicing. Proc Natl Acad Sci USA, 88:2692-6.

Yoshida T, Shiraishi T, Horinaka M, et al. 2007. Lipoxygenase inhibitors induce death receptor 5/TRAIL-R2 expression and sensitize malignant tumor cells to TRAIL-induced apoptosis. Cancer Sci, 98:1417-23.

Yoshimura R, Sano H, Masuda C, et al. 2000. Expression of cyclooxygenase2 in prostate carcinoma. Cancer, 89:589-96.

Yoshimura R, Matsuyama M, Tsuchida K, et al. 2003. Expression of lipoxygenase in human bladder carcinoma and growth inhibition by its inhibitors. $J$ Urol, 170:1994-9.

Yoshimura R, Matsuyama M, Kawahito Y, et al. 2004. The effect of cyclooxygenase-2 inhibitors on urological cancer cells. Int J Mol Med, 13:789-93. 